\title{
PROGRESSO NA SELEÇÃo dE PROGÊNIES dE TOMATE RESISTENTES À MURCHA BACTERIANA ATRAVÉS DA AVALIAÇÃO EPIDEMIOLÓGICA DA DOENÇA.
}

\author{
Hiroshi NODA ${ }^{1}$, Francisco Manoares MACHADO'
}

\begin{abstract}
RESUMO - Dados obtidos em experimentos realizados durante a década $83 / 92$ pelo Programa de Melhoramento Genético do Tomateiro foram utilizados para avaliar a eficiência da utilização do parâmetro epidemiológico Taxa de Infecção para seleção de progênies resistentes ao patógeno Pseudomonas solanacearum. Foram obtidas evidências que as progênies selecionadas de uma geração para a seguinte apresentaram níveis crescentes de resistência e maior capacidade produtiva sob condição de cultivo em solos infestados pelo patógeno, usando-se como padrões de susceptibilidade variedades do grupo Santa Cruz e de resistência a variedade Caraiba. A Taxa de Infeção consegue detectar elevado número de contrastes significativos quando comparada com outros parâtnetros que não consideram a resistência como resultante de um processo na qual a expressão é modificada com o tempo.
\end{abstract}

Palavras-chave: tomate, Pseudomonas solanacearum, murcha bacteriana, melhoramento genético do tomateiro, avaliação epidemiológica de doença em plantas.

Selection Progress of Resistant Tomato Progenies to Bactarial Wilt Disease by Epidemiological Evaluation.

SUMMARY - Data from experiments carried out during the decade $83 / 92$ by the Tomato Breeding Program of the INPA were utilized to evaluate the efficience of the epidemiologic parameter Infection Rate to select resistant progenies to Pseudomonas solanacearum. Evidence were obtained that selected progenies from one to the sequence generation showed increased levels of resistance to the pathogen and yield capacity under infested soils cultivation, using standards of susceptible (Santa Cruz group) or resistante (Caraiba) varieties. The Infection Rate is able to detect high number of significant contrasts when compared to another parameter which do no consider the resistance as a resultant of a process which the expression change with the time.

Key-words: tomato, Pseudomonas solanacearum, bacterial wilt, tomato breeding, epidemiological evaluation of plant disease

\section{INTRODUÇÃO}

Os programas de melhoramento genético do tomateiro para resistência à murcha bacteriana, causada por Pseudomonas solanacearum, têm encontrado desafios metodológicos na avaliação de níveis de resistência genética do hospedeiro. Segundo VILLAREAL (1980) a reação de resistência do tomateiro ao patógeno é geneticamente complexa e de acordo com GALEGLY \& WALKER (1949) é fortemente associada às condições do ambiente. Cultivares que apresentam reação de resistência à murcha bacteriana sob determinadas condições de cultivo não expressam esse caráter quando expostas aos ambientes desfavoráveis. No Brasil as

\footnotetext{
Instituto Nacional de Pesquisas da Amazônia, Coordenação de Pesquisas em Ciências
} Agronômicas, Caixa Postal 478,69011-970 - Manaus, Amazonas, Brasil. 
cultivares Saturn e Venus, consideradas resistentes, apresentaram reação de susceptibilidade à $P$. solanacearum quando avaliadas em casas de vegetação com temperaturas máximas (acima de $30^{\circ} \mathrm{C}$ ), consideradas elevadas para o tomateiro (COUTO et al., 1979; MARTINS et al., 1988).

Uma vez que áreas de ocorrência de $P$. solanacearum são as regiões tropicais de baixa altitude, onde as condições de ambiente não são consideradas favoráveis ao cultivo do tomateiro (temperatura e umidade elevadas) torna-se necessário que as cultivares resistentes à murcha bacteriana expressem esse caráter sob aquelas condições.

Dois tipos de ensaios tem sido utilizados para avaliação da reação de resistência do tomateiro ao patógeno: a triagem em casas de vegetação de plantas na fase juvenil e triagem no campo, sob condições de solos infestados pelo patógeno (NODA et al., 1986). O primeiro método oferece a vantagem de tornar possivel o ensaio usando-se grande número de indivíduos em pouco espaço, de permitir o contrôle das condições do ambiente que possam interferir na expressão do caráter. Entretanto, os resultados obtidos com plântulas nem sempre estão de acordo com aqueles obtidos em testes com plantas adultas (MEW \& HO, 1976). Os ensaios realizados em solos naturalmente infestados pelo patógeno apresentam a desvantagem de restringir o número de indivíduos mas, por outro lado, constituem uma simulação mais perfeita das condições naturais da interação hospedeiro $\mathrm{X}$ patógeno $\mathrm{X}$ ambiente e oferecem a vantagem adicional de permitir a estimação do grau de associação entre níveis de doença na população de plantas e o consequente prejuizo no rendimento econômico (NODA et al., 1986).

Este trabalho descreve a avalia a eficiência do uso de um parâmetro epidemiológico como critério de seleção de progênies de tomate visando elevar os niveis de resistência genética à murcha bacteriana.

\section{MATERIAL E MÉTODOS}

Os dados utilizados neste trabatho foram obtidos de experimentos realizados dentro do Programa de Melhoramento Genético do Tomateiro do INPA, no periodo 1983-92. Este programa tem como objetivo desenvolver variedades de tomate para cultivo no trópico úmido brasileiro. Dessa maneira, hierarquicamente, priorizou-se como meta o desenvolvimento de variedades geneticamente resistentes à murcha bacteriana, causada por $P$. solanacearum, e tolerância ao cultivo sob condições de temperatura e umidade elevadas.

O programa foi iniciado em 1976 quando foram realizadas as avaliações das introduções existentes na coleção do INPA e efetuaram-se os cruzamentos entre os materiais considerados mais promissores. Em 1983 realizouse a avaliação de progênies F4 e F5 de dez cruzamentos conduzidas pelo método genealógico e selecionadas sob condição de cultivo em solo natural- 
mente infestado por $P$. solanacearum (NODA et al., 1986). A partir dos resultados obtidos naquela avaliação considerou-se como o mais promissor o cruzamento HT-16, resultante da hibridação entre a introdução $\mathrm{IH}-40$, procedente do IRAT (Caiena, Guiana Francesa) com a introdução UH-7976, da Universidade de Hawaii (EUA). Decidiu-se pelo avanço das gerações e seleção dentro deste cruzamento, obtendo-se, em 1988, uma cultivar com resistência poligênica ao patógeno, denominado Yoshimatsu (NODA et al., 1988).

0 método de triagem é o mesmo descrito por KURIYAMA (1975), para os ensaios de campo no qual as plantas com ausência ou pouco sintomas da doença no final do ciclo são consideradas resistentes. A presença da bactéria nos feixes vasculares é constatada pelo método descrito por KIRÁLY et al., (1974) e consiste na exudação de células bacterianas na forma de um líquido de coloração leitosa quando pequenos pedaços de tecido afetado pelo patógeno são colocados sobre uma placa de vidro com água.

Os experimentos foram realizados em áreas com solos naturalmente infestados por $P$. solanacearum nos ecossistemas de terra firme (Estação Experimental de Hortaliças do INPA, em Manaus) e várzea (Estação Experimental de Ariaú, à margem do Rio Solimões, no município de Iranduba). As mudas foram produzidas em copos de plástico com solo esterilizado com brometo de metila. Nos experimentos em solo de terra firme normalmente são realizadas adubações usuais de plantio (adubo orgânico, macro e micronutrientes minerais) e em cobertura (geralmente, nitrogênio). Na várzea, por ser constituida de solos de alta fertilidade, é realizada somente adubação nitrogenada, em cobertura. O transplante geralmente é realizado quatro semanas após a semeadura.

As avaliações de ocorrência de murcha bacteriana são iniciadas após o transplante das mudas no campo e, em intervalos semanais, faz-se o registro das plantas afetadas pela doença, anotando-se, também, a posição das plantas nas parcelas.

As caracteristicas avalidas foram:

a. Taxa de Infecção (QR), calculado pela fórmula descrita por PLANK (1963), para doenças sem multiplicação:

$$
\mathrm{QR}=\frac{1}{t_{2}-\mathrm{t}_{1}}\left(\log _{\mathrm{e}} \frac{1}{1-\mathrm{ID}_{2}}-\log _{\mathrm{e}} \frac{1}{1-\mathrm{ID}_{1}}\right)
$$

onde:

$\mathrm{t}_{1}$ : número de dias entre a data do transplante e a data da $1^{\mathrm{a}}$ avaliação

$t_{2}$ : número de dias entre a data do transplante e a data da última avaliação

I. $D_{1}$ : Indice de Doença na $1^{\mathrm{a}}$ avaliação

I. $\mathrm{D}_{2}$ : Indice de Doença na última avaliação

Os valores do Índice de Doença (I.D.) foram obtidos através da seguinte fórmula:

$$
\text { I.D. }=\frac{\text { P.D. }}{\text { P.T. }}
$$


onde,

P.D.: número de plantas na parcela com sintoma de murcha bacteriana na parcela

P.T: número total de plantas

b. Produção total de frutos (P), expressa em gramas/cova, correspondendo ao peso total de frutos coletados em todas as etapas de colheita.

$\mathrm{O}$ delineamento experimental foi definido em função do número de tratamentos a serem avaliados. Usou-se o delineamento em blocos casualizados se o número de tratamentos não ultrapassasse a vinte. Acima disso usouse o delineamento em látice quadrado (COCHRAN \& COX, 1957). Para a análise de variância, os dados expressos em QR sofreram transformação logaritmica ou para $\operatorname{arcsen}(x+0,5)^{1 / 2}$, de acordo com procedimento preconizado por STEEL \& TORRIE (1960). As equações de regressão de $\log _{\mathrm{e}}[\mathrm{I} /(\mathrm{I}$ I.D.)] sobre o número de dias após o transplante foram obtidos utilizando-se as médias das repetições. Usou-se o teste t para estimar a significância do valor do coeficiente de correlação $r$, segundo o procedimento preconizado por PIMENTEL GOMES (1978). Para todos os caracteres estudados, as médias dos tratamentos foram testadas contra as médias da variedade Santa Cruz, usada como testemunha susceptivel ou Caraiba, usada como testemunha resistente, ao nivel de $5 \%$ de probabilidade, através do teste $\mathrm{t}$, segundo procedimento preconizado por LITTLE \& HILLS (1972) ou teste de Dunnet (STEEL \& TORRIE, 1960).

\section{RESULTADOS E DISCUSSÃO}

Durante o processo de avaliação e seleção, no período de 1983/92, observou-se, consistentemente, a ocorrência de contrastes significativos para os caracteres de resistência à Pseudomonas solanacearum e de produção de frutos sob condição de cultivo em solos infestados pelo patógeno (Tab. 1). As progênies selecionadas para as etapas subsequentes apresentaram maiores niveis de resistência ao patógeno e maiores capacidades de produção em sơlos infestados quando comparadas tanto contra a testemunha susceptivel (grupo Santa Cruz) como contra a testemunha resistente (Caraiba). Como já relatado anteriormente por NODA et al., (1986), o caráter QR, por se tratar de um parâmetro épidemiológico, consegue detectar maiores números de contrastes significativos quando comparado com outros parâmetros que não consideram a resistência do hospedeiro como uma resultante de um processo cuja expressão varia em função do tempo.

Em relação à precisão experimental, constata-se que, de maneira geral, ocorrem maiores magnitudes dos coeficientes de variação experimental para o caráter produtivo quando comparados com aqueles observados para o parâmetro Taxa de Infecção, que expressa niveis de resistência. Esses dados sugerem que, apesar de tratar-se de um caráter de herança complexa (RUSSEL, 1978), a magnitude da herdabilidade da resistência do toma- 
Tabela 1. Significâncias estatisticas e coeficientes de variação experimental observadas em experimentos de avaliação, para resistência à murcha bacteriana causada por Pseudomonas solanacearum, de progênies de tomate do eruzamento HT-16, no período de $1983 / 1992$. Manaus, 1993.

\begin{tabular}{|c|c|c|c|c|c|c|c|}
\hline \multirow{2}{*}{\multicolumn{2}{|c|}{$\begin{array}{c}\text { Periodo / } \\
\text { Geração de } \\
\text { Seleção }\end{array}$}} & \multicolumn{4}{|c|}{ Contrastes significativos (TESTE $t$ ) } & \multirow{2}{*}{\multicolumn{2}{|c|}{$\begin{array}{l}\text { Coeficientes de } \\
\text { Variaçáo } \\
\text { Experimental (\%) }\end{array}$}} \\
\hline & & \multicolumn{2}{|c|}{ Taxa de Infeç̧ăo } & \multicolumn{2}{|c|}{ Produção } & & \\
\hline & & S.C. vs HT-16 & Caraiba vs HT-16 & S.C. vs HT - 16 & Caraiba vs HT-16 & QR & Produçăo \\
\hline 1983 & F4 & * & - & - & . & 12.12 & 36.69 \\
\hline 1984 & F5 & (a) & (a) & (a) & (a) & (a) & (a) \\
\hline 1986 & F6 & * & $\because$ & $\because$ & $\because$ & 2.89 & 32.41 \\
\hline 1987 & F7 & * & * & $*$ & - & 1.11 & 20.07 \\
\hline 1988 & F8 & (a) & (a) & (a) & (a) & (a) & (a) \\
\hline 1991 & F9 & $*$ & $\because$ & $*$ & $\because$ & 1.76 & 14.79 \\
\hline 1992 & F10 & * & - & - & * & 23.42 & 13.46 \\
\hline
\end{tabular}

* Contrastes estatisticmente significativos, ao nivel de $5 \%$ de probabilidade (Teste $t$ ou Dunnet)

(a) Dados não analisados estatisticamente

S.C. Cultivar do grupo Santa Cruz

teiro ao patógeno $P$. solanacearum parece ser superior em relação as características produtivas. Mesmo porque, quando cultivado sob condição de solo infestado pelo patógeno, a resistência genética é um componente que interfere decisivamente no ciclo de vida e capacidade produtiva do hospedeiro.

Os dados apresentados na Tabela 2 permitem visualizar uma tendência ascendente dos niveis de resistência das progênies HT - 16 quando comparadas com os referenciais constantes. Supõese que a ausência completa da doença nas progênies, observada nas avaliações realizadas nas gerações $\mathrm{F} 8$ (1988) e F 10 (1992), devem-se aos menores níveis do potencial de inóculo do solo ocorridos naqueles experimentos. Os dados sobre os níveis de resistência obtidos na testemunha resistente Caraiba $(\mathrm{QR}=0,0079)$, em 1988 e 1992 ( $Q R=0,0039)$, que foram os mais elevados considerando-se todo o período de 1984 a 1992 , reforçam a sugestão da ocorrência de níveis mais baixos de potencial de inóculo em 1988 e 1992. Por outro lado, nos ensaios realizados em 1987 e 1991, para avaliação das progênies F 7 e F 9, respectivamente, observaram-se os maiores valores da Taxa de Infecção para a testemunha Caraiba. Mesmo naquelas condições, as resistências estimadas das progênies selecionadas foram 5 a 17 vezes mais elevadas em relação à cultivar Caraiba, na geração $F \quad 7$ e de 6 a 29 vezes superiores em relação à mesma testemunha, na geração $\mathrm{F} 9$.

$\mathrm{O}$ uso de testemunhas susceptivel e resistente constantes mostrou ser muito recomendável para a avaliação do nivel de contaminação do solo com o patógeno em cada experimento e esse procedimento mostrou ser um recurso muito valioso para se poder estimar o ganho genético ocorrido no processo de seleção das progênies.

A Figura 1 mostra o progresso da murcha bacteriana no período de 42 dias compreendido entre as sete etapas 
Tabela 2. Estimativas de progresso nos níveis de resistência genética de progênies HT-16 de tomate à Pseudomonas solanacearum tomando-se como referenciais constantes cultivares susceptiveis (Grupo Santa Cruz) e resistente (Caraiba), no período 83/93. Manaus, 1993

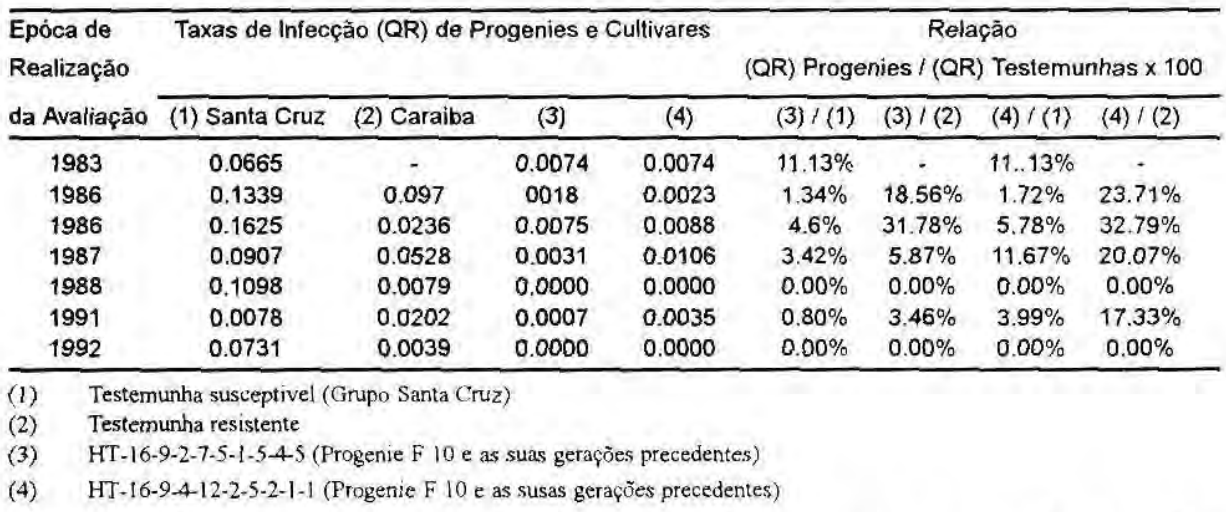

semanais de medições, referente ao experimento de avaliação das progênies do ciclo de seleção $F$ 9, realizado no ano de 1991, no ecossistema de várzea. Observa-se que os valores do coeficiente $b$ das equações de regressão lineares estimam a Taxa de Infecção (QR) ajustada (NODA et al., 1986). Para as cultivares Santa Cruz Kada, Santa Cruz Angela Hiper e C-38, encontrou-se associações estreitas e significativas entre o tempo de avaliação e severidade da doença. Desse modo, os dados obtidos nessa série de experimentos confirmam as observações de NODA et al., (1986) no sentido da doença "murcha bacteriana" do tomateiro apresentar uma característica epidemiológica bem definida, na qual niveis elevados de resistência conferida por um genótipo são devidos aos baixos niveis de velocidade do progresso da doença na população de hospedeiro. Para a cultivar Caraiba, o valor da estimativa do coeficiente de correlação linear foi significativo ao nível de $10 \%$ de probabilidade, pelo teste $\mathrm{t}$. Isto ocorreu em função do atraso apresentado por essa cultivar para o início de ocorrência dos sintomas da doença. A ausência, na Figura 1, das regressãoes lineares das progênies $F 9$ do cruzamento HT-16, também avaliadas naquele experimento, é explicada pelo ocorrência quase nula de doença naquelas progênies $(\mathrm{QR}=0,0007$, para HT-16-9-2-7-5-1-5-4 e QR $=0,0035$ para HT-16-9-4-12-2-5-2-1) e pelo periodo extremamente longo para inicio do aparecimento dos sintomas da doença. Em ambas progênies os sintomas de murcha foram constatados somente na última etapa de medição de ocorrência de doença ( $7^{a}$ semana), ou seja, aos 81 dias após o transplante das mudas no campo.

\section{AGRADECIMENTOS}

Os autores manifestam os agradecimentos ao BMFT (Ministério de Ciência e Tecnologia da República Federal da Alemanha) pela subvenção 
Figura 1. Progresso da doença murcha bacteriana em cultivares e progênies de tomateiro cultivadas sob condição de solo naturalmente infestado por Pseudomonas solanacearum em experimento realizado no ano de 1991, no ecossistema de várzea. Estação Experimental do Ariaú. Iranduba, AM.

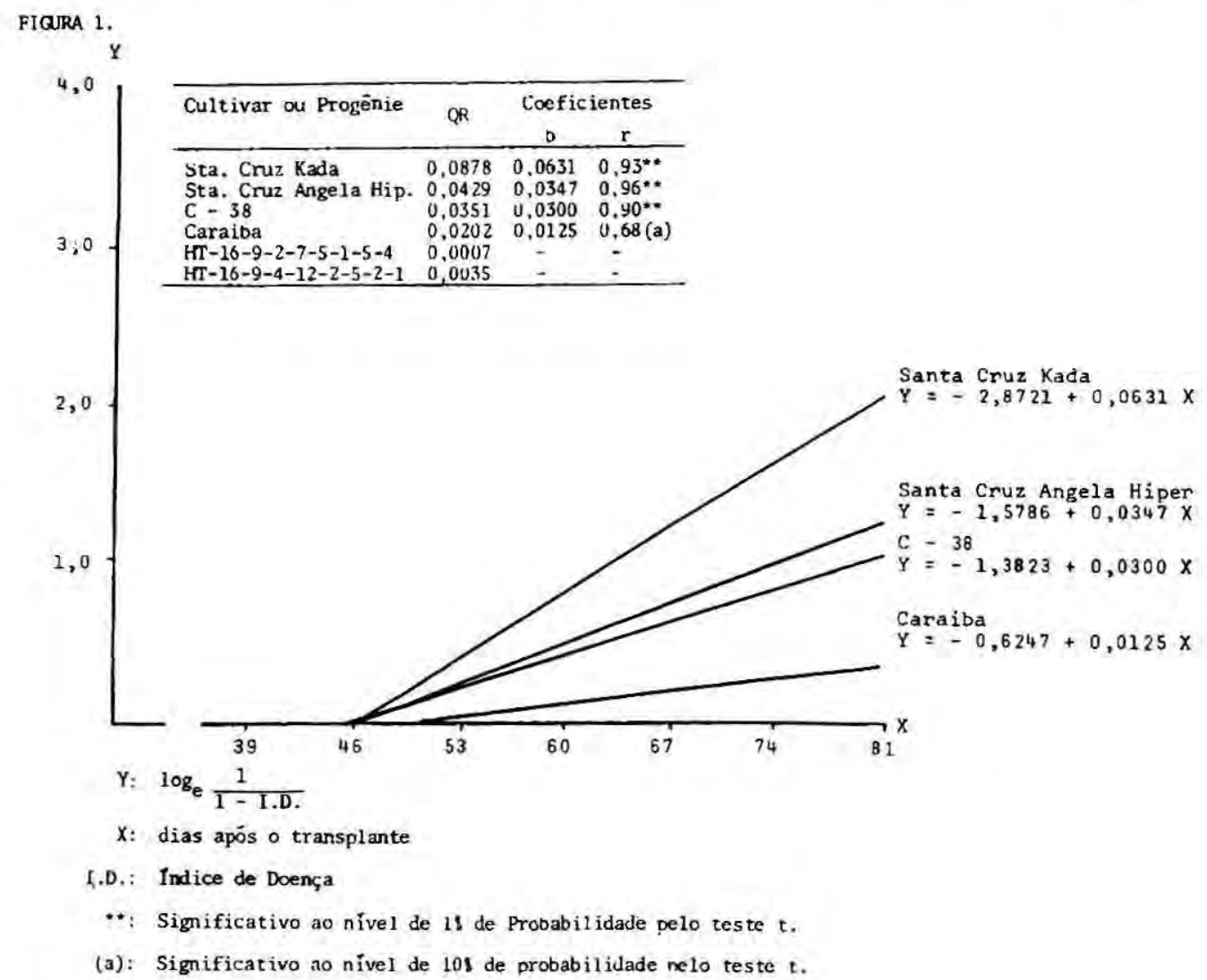


das atividades de pesquisa do Programa de Melhoramento Genético de Hortaliças do Instituto Nacional de Pesquisas da Amazônia, no ecossistema de várzea, através do Projeto Várzea - Convênio INPA/Instituto Max Planck, a partir de 1990.

\section{Bibliografia citada}

COCHRAN, W. G.; COX, G. M. 1957. Experimental Designs. John Wiley \& Sons. New York. 593 p.

COUTO, F. A. A.; MIZUBUTI, A.; MATSUOKA, K.; CAMPOS, J. P. 1979. Avaliação do grau de resistência à Pseudomonas solanacearum de cinco cultivares de tomateiro e das progênies resultantes do cruzamento entre eles. Revista de olericultura, XVII:48-58.

GALEGLY, M. E.; WALKER, J. P. 1949. Relation of environmental factors to bacterial wilt of tomato. Phytopathology, 39:932-946.

KIRÁLY, Z; KLEMENT, Z.; SOLYMOSY, F; VÖRÖS, J. 1970. Methods in Plant Pathology with Special Reference to Breeding for Disease Resistance. Akadémiai Kiadó. Budapest. 509 p.

KURIYAMA, T. 1975. Testing methods for breeding disease-resistant vegetables in Japan. Jpn. Agric. Res. Q., 9:96-100.

LITTLE, T. M; HILLS, F. J. 1972. Statistical Methods in Agricultural Research. University of California, Davis. 242 p.
MARTINS, O. M.; REIFSCHNEIDER, F. J. B.; TAKATSU, A.; PESSOA, H. B. S. V. 1988. Fonte de resistência em tomateiro à Pseudomonas solacearum. Horticultura Brasileira, 6(2):17-19.

MEW, T. W: HO, W. C. 1976. Varietal resistance to bacterial wilt in tomato. Plant Disease Reporter, 60: 264.

NODA, H.; PAHLEN, A. von der; SILVA F'., D. F. 1986. Avaliação da resistência de progênies de tomate à murcha bacteriana em solo naturalmente infestado por Pseudomonas solanacearum. Rev. Brasil. Genet., IX (1):55-66.

NODA, H.; MACHADO, F. M; SILVA F'., D F. 1988. Yoshimatsu, cultivar de tomate para cultivo no Trópico Úmido. Horticultura Brasileira, 6(1):70. (resumo).

PIMENTEL GOMES, F. 1978. Curso de Estatistica Experimental. Nobel. São Paulo. $430 \mathrm{p}$. + tabelas.

PLANK, J. E. van der. 1963. Plant Disease: Epidemics and Control. Academic Press. New York. 349 p.

STEEL, R. G. D;; TORRIE, J. H. 1960. Principles and Procedures of Statistics with Special Reference to the Biological Sciences. McGraw-Hill. New York. 481 p.

RUSSEL, G. E. 1978. Plant Breeding for Pest and Disease Resistance. Butterworths. London and Boston. $485 \mathrm{p}$.

VILLAREAL, R. L. 1980. Tomatoes in the Tropics. Westview Press. Boulder. 174 p. 